\title{
Analysis of Charged Cyclodextrin Derivatives by On-Line Capillary Electrophoresis-Ionspray-Mass Spectrometry
}

\author{
Yoshihide TANaKA*†, Yasuhiro Kishimoto* and Shigeru Terabe** \\ *Department of Analytical Chemistry, Nippon Boehringer Ingelheim Co. Ltd., \\ 3-10-1, Yato, Kawanishi, Hyogo 666-01, Japan \\ **Faculty of Science, Himeji Institute of Technology, Kamigori, Hyogo 678-12, Japan
}

\begin{abstract}
On-line capillary electrophoresis-ionspray-mass spectrometry (CE-ISP-MS) was applied to a composition analysis of charged cyclodextrin (CD) derivatives. Quaternary ammonium $\beta$-CD (QA- $\beta$-CD) and carboxymethylated $\gamma$-CD (CM- $\gamma$ $\mathrm{CD}$ ), which were used as chiral selectors for enantiomer separations by $\mathrm{CE}$, were analyzed. As for QA- $\beta$-CD, eight components having different degrees of the quaternary ammonium substitution could be identified based on their mass spectra. The components were detected as either molecular ions or fragment ions. On the other hand, six components of CM$\gamma$-CD were detected as bivalent molecular ions. Such composition analyses were difficult using CE with only the UV detector. CE-MS was found to be a promising technique for a composition analysis of mixed compounds.
\end{abstract}

Keywords Capillary electrophoresis-mass spectrometry, ionspray interface, composition analysis, charged cyclodextrin

Cyclodextrins (CDs) and their derivatives are most widely employed as chiral selectors for enantiomer separations by capillary electrophoresis (CE).,2 In particular, many applications with charged $\mathrm{CD}$ derivatives have been reported in recent years because charged CDs are much superior to neutral CDs for the separation of oppositely charged enantiomers. ${ }^{3-5}$ However, most commercial CD derivatives consist of a mixture having different degrees of substitution. Each component of the $\mathrm{CD}$ has a different binding constant with the enantiomer. Furthermore, the different electrophoretic mobility of each component may cause some problems, such as peak broadening for enantiomeric separations. ${ }^{6,7}$ The constant composition of the CD is particularly important for obtaining good reproducibility in enantiomeric separations.

Charged CDs can be easily separated by capillary zone electrophoresis (CZE), as reported in several papers. ${ }^{3,8-10}$ Because CDs are weakly UV absorbing, the indirect UV detection method has usually been used. In a previous study ${ }^{10}$, we also separated a quaternary ammonium $\beta$-CD (QA- $\beta$-CD) by CZE with an indirect UV detection method. Although it was concluded that QA- $\beta$-CD consisted of at least six components, each peak could not be identified by only the indirect UV detection method. The coupling of CE with mass spectrometry (MS) is a promising technique for such a composition analysis because information on the molecular masses is obtained.

Several interfaces have been developed since the first demonstration of on-line CE-MS employing an electro-

\footnotetext{
$\doteqdot$ To whom correspondence should be addressed.
}

spray ionization interface in 1987. ${ }^{11}$ The interface is the most important for obtaining high sensitivity for MS. Pneumatically assisted electrospray (ionspray, ISP) ionization is widely used as an interface between $\mathrm{CE}$ and MS. ${ }^{12}$ At present, a commercial ISP interface is available for CE-MS as it is. In this paper, we discuss the composition analysis of some charged CD derivatives by on-line CE-ISP-MS. Some advantages and disadvantages of the MS detection are also considered.

\section{Experimental}

\section{Apparatus}

A Hewlett Packard 3D CE instrument (Yokogawa Analytical Systems, Tokyo, Japan) and a Perkin-Elmer Sciex API-300 triple quadrupole MS instrument (Perkin-Elmer Japan, Yokohama, Japan) equipped with an ISP interface were employed. A fused-silica capillary of $50 \mu \mathrm{m}$ i.d. and $150 \mu \mathrm{m}$ o.d. (GL Science, Tokyo, Japan) was coated with linear polyacrylamide. ${ }^{13}$ A capillary of $80 \mathrm{~cm}$ in total length was incorporated into a user-assembled capillary cartridge. A Hewlett Packard Vectra XM Series $3(5 / 120)$ computer was used to control the CE instrument. The MS instrument control and data collections were performed with a Macintosh computer (Model 8500/120).

\section{Reagent}

Quaternary ammonium $\beta$-CD (QA- $\beta$-CD) was purchased from Spelco (Bellefonte, PA, USA). Carboxymethylated $\gamma$-CD (CM- $\gamma$-CD) was obtained 
Table 1 Characterics of charged CDs obtained from the specifications by the suppliers

\begin{tabular}{lll}
\hline & \multicolumn{1}{c}{$\begin{array}{c}\text { Quaternary ammonium } \beta-\mathrm{CD} \\
(\mathrm{QA}-\beta-\mathrm{CD})\end{array}$} & \multicolumn{1}{c}{$\begin{array}{c}\text { Carboxymethylated } \gamma-\mathrm{CD} \\
(\mathrm{CM}-\gamma-\mathrm{CD})\end{array}$} \\
\hline Substituent & $-\mathrm{CH}_{2} \mathrm{CH}(\mathrm{OH}) \mathrm{CH}_{2} \mathrm{~N}^{+}\left(\mathrm{CH}_{3}\right)_{3} \mathrm{Cl}^{-}$ & $-\mathrm{CH}_{2} \mathrm{COOH}$ \\
Average formula & $\mathrm{C}_{63} \mathrm{H}_{119} \mathrm{O}_{38.5} \mathrm{~N}_{3.5} \mathrm{Cl}_{3.5}$ & $\mathrm{C}_{54} \mathrm{H}_{86} \mathrm{O}_{46}$ \\
Average molecular mass & 1665.8 & 1472 \\
Average degree of substitution & 3.5 & 3.2 \\
Composition & $c a .96 \%$ QA- $\beta-\mathrm{CD}, c a .4 \% \mathrm{NaCl}^{\mathrm{a}}$ & $>90 \%$ in acidic form, \\
& & $<10 \%$ as sodium salt, $<5 \% \mathrm{NaCl}$ \\
\hline
\end{tabular}

a. The value obtained from our analysis by CZE (ref. 10).

from Cyclolab (Budapest, Hungary). The characteristics of their CDs are given in Table 1. All other reagents were of analytical grade or HPLC grade. Water was purified with a Milli-Q Labo system (Nihon Millipore, Yonezawa, Japan).

\section{Procedure}

For the optimization of MS, a sample solution of QA$\beta$-CD was prepared in $0.05 \%$ formic acid containing $50 \%$ methanol (ca. $5 \mathrm{mg} / \mathrm{ml})$, and that of CM- $\gamma$-CD in $20 \mathrm{mM}$ ammonium acetate solution containing 50\% methanol (ca. $1 \mathrm{mg} / \mathrm{ml})$. The sample solutions were infused into the ISP interface directly at $5 \mu \mathrm{l} / \mathrm{min}$ with a Harvard Apparatus syringe pump (Model 11, South Natick, MA, USA). The ionspray voltage was maintained at $5 \mathrm{kV}$ for $\mathrm{QA}-\beta-\mathrm{CD}$ and at $-4.5 \mathrm{kV}$ for $\mathrm{CM}-\gamma-$ CD.

In order to study the effects of organic solvents in sheath liquids, each sheath liquid was delivered at 5 $\mu \mathrm{l} / \mathrm{min}$. CD solutions in water (ca. $10 \mathrm{mg} / \mathrm{ml})$ were infused into the ISP interface by the CE instrument. The injection end of a CE capillary was immersed in a sample solution, and the sample solution was pneumatically injected continuously at $5 \mathrm{kPa}$ (50 mbar).

Upon the analysis of QA- $\beta$-CD by CE-MS, a $0.2 \%$ formic acid solution was used as a running solution. As for CM- $\gamma-\mathrm{CD}$, a $40 \mathrm{mM}$ ammonium acetate buffer (pH 5.0) was used as a running solution. All running solutions were filtered through a $0.22 \mu \mathrm{m}$ syringe-type membrane filter prior to use. A mixture of each running solution and methanol (1:1) was used as the sheath liquid at $5 \mu \mathrm{l} / \mathrm{min}$. Sample solutions for CE-MS analysis were prepared by dissolving a CD in water ( $c a .10$ $\mathrm{mg} / \mathrm{ml}$ for QA- $\beta$-CD and $c a .5 \mathrm{mg} / \mathrm{ml}$ for CM- $\gamma-\mathrm{CD})$. The capillary was rinsed with the running solution for 5 min at $94 \mathrm{kPa}$ prior to each run. At the beginning and end of each day, the capillary was washed with the capillary wash solution (Bio-Rad Laboratories, Cat No. 148-5022, Hercules, CA, USA) and water at $94 \mathrm{kPa}$ for more than $10 \mathrm{~min}$ each. A sample solution was injected at $5 \mathrm{kPa}$ for $8 \mathrm{~s}$. When QA- $\beta$-CD was analyzed, 30 $\mathrm{kV}$ was applied at the injection end of the capillary. The ionspray voltage (at the other end of the capillary) was not applied during sample injection and $5 \mathrm{kV}$ was applied after $1 \mathrm{~min}$ from each start (the net voltage across the capillary was $25 \mathrm{kV}$ ). Spectra were acquired by scanning the first mass filter quadrupole $(\mathrm{Q} 1)$ from $m / z 300$ to $m / z$ 1500. As for CM- $\gamma-\mathrm{CD},-30 \mathrm{kV}$ was applied at the injection end of the capillary. Because $-4.5 \mathrm{kV}$ of the ionspray voltage was applied, the net voltage across the capillary was $-25.5 \mathrm{kV}$. The spectra were acquired by scanning Q1 from $\mathrm{m} / \mathrm{z} 600$ to $\mathrm{m} / \mathrm{z}$ 900 .

\section{Results and Discussion}

\section{Mass spectra of charged CDs without separation}

Firstly, we measured the mass spectra of charged CDs by infusing each CD solution directly into the ISP interface using a syringe pump. A positive-ion mode was used for the detection of QA- $\beta$-CD, and a negative-ion mode for that of CM- $\gamma$-CD. In these measurements, the MS conditions, such as the orifice voltage and focusing ring potential, were optimized to give high intensities of the peaks. The same conditions were used for the following CE-MS experiments. The mass spectra and the optimum MS conditions are given in Fig. 1 and Table 2, respectively. For QA- $\beta$-CD, the components were observed as various ionic forms,

Table 2 Operation conditions of the MS instrument in the composition analyses of charged CDs

\begin{tabular}{lrr}
\hline \multicolumn{1}{c}{$\begin{array}{c}\text { Instrument } \\
\text { parameter }\end{array}$} & $\begin{array}{r}\text { Analysis of } \\
\text { QA- } \beta \text {-CD }\end{array}$ & $\begin{array}{r}\text { Analysis of } \\
\text { CM- } \gamma \text {-CD }\end{array}$ \\
\hline Electrospray needle voltage & $5.0 \mathrm{kV}$ & $-4.5 \mathrm{kV}$ \\
Nebulizer gas (air) & $1.231 / \mathrm{min}$ & $1.231 / \mathrm{min}$ \\
Curtain gas (nitrogen gas) & $1.081 / \mathrm{min}$ & $1.081 / \mathrm{min}$ \\
Orifice voltage & $50 \mathrm{~V}^{\mathrm{a}}$ & $-50 \mathrm{~V}$ \\
& $100 \mathrm{~V}^{\mathrm{b}}$ & \\
Focusing ring potential & $350 \mathrm{~V}^{\mathrm{a}}$ & $-350 \mathrm{~V}$ \\
& $400 \mathrm{~V}^{\mathrm{b}}$ & $10 \mathrm{~V}$ \\
High pressure entrance & $-10 \mathrm{~V}$ & $10.5 \mathrm{~V}$ \\
$\quad$ quadrupole (Q0) & & $15 \mathrm{~V}$ \\
Inter-quadrupole lens 1 (IQ1) & $-10.5 \mathrm{~V}$ & $12 \mathrm{~V}$ \\
Stubbies (ST) & $-15 \mathrm{~V}$ & \\
First resolving quadrupole & $-14.5 \mathrm{~V}$ & $18 \mathrm{~V}$ \\
$\quad$ RO1) & & \\
Inter-quadrupole lens 2 (IQ2) & $-30 \mathrm{~V}$ & \\
\hline
\end{tabular}

a. $m / z=300-1000$.

b. $m / z=1000-1500$. 

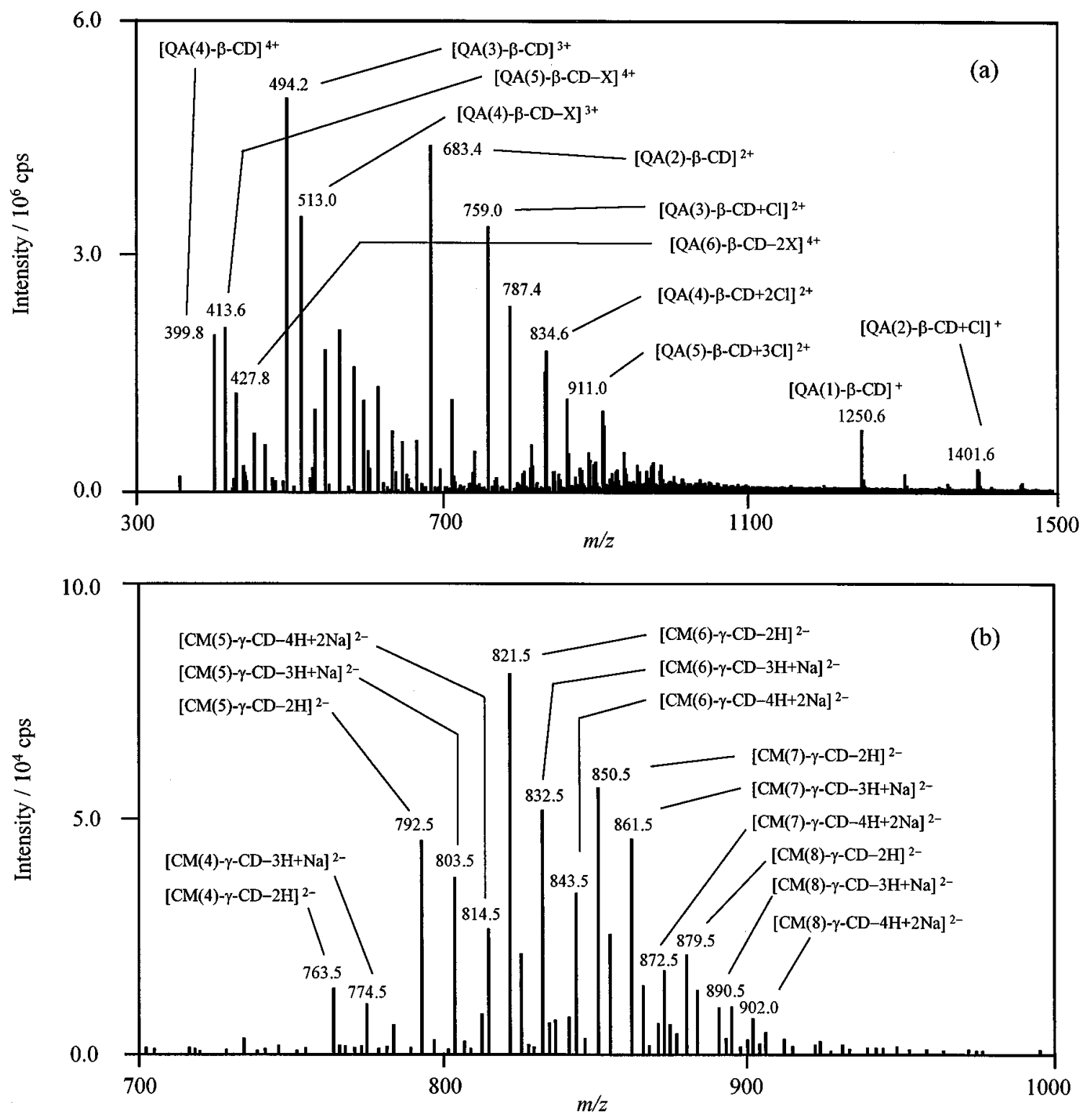

Fig. 1 Mass spectra of charged CDs. (a) QA- $\beta$-CD in $0.05 \%$ formic acid containing $50 \%$ methanol ( $5 \mathrm{mg} / \mathrm{ml}$ ), (b) $\mathrm{CM}-\gamma-\mathrm{CD}$ in $20 \mathrm{mM}$ ammonium acetate containing $50 \%$ methanol $(1 \mathrm{mg} / \mathrm{ml}) . \mathrm{X}$ is the fragment ion $\mathrm{HN}^{+}\left(\mathrm{CH}_{3}\right)_{3}$ of QA- $\beta$-CD.

which were chloride adducts and the fragment ions as well as molecular ions. On the other hand, all components of CM- $\gamma$-CD were detected as bivalent ions. Sodium adduct ions were also detected.

\section{$C E-M S$ of $Q A-\beta-\mathrm{CD}$}

In our previous study ${ }^{10}$, QA- $\beta$-CD was analyzed by CZE with the indirect UV detection method. As the running solution, $50 \mathrm{mM}$ sodium phosphate buffer $(\mathrm{pH}$ 6.0) containing pyridinium ion as the UV absorbing reagent was used. However, a phosphate buffer solution is not suitable for MS detection, due to the involatile components. Volatile salts, such as ammonium acetate and ammonium formate, are usually utilized for CE-MS. ${ }^{12}$ For the detection of cationic analytes by MS, acidic buffers should be preferred to ensure a sta- ble formation of positively charged droplets during the electrospray process. Moreover, the $\mathrm{pH}$ of the running buffer may not cause changes in the electrophoretic mobilities of the components of QA- $\beta$-CD because of quaternary ammonium groups. Therefore, a $0.2 \%$ formic acid solution was used as the running solution in this analysis. The $\mathrm{pH}$ value of the solution was $c a$. 2.5.

In CE-MS, a sheath liquid is commonly used to complete the electrical circuit through the capillary and to obtain highly charged droplets during the electrospray process. Some organic-solvent mixtures have been used as the sheath liquid because the organic solvents are effective in enhancing the stability of the electrospray. ${ }^{12,14}$ In this study we tested methanol, ethanol, 2propanol and acetonitrile at concentrations of $50 \%$ in the running solution. The peak intensity of each com- 
ponent of QA- $\beta$-CD was not significantly influenced, except for 2-propanol, which decreased the peak intensity (data not shown). The peak intensity was slightly decreased when the concentration of methanol was decreased. Accordingly, we used a mixture of a running solution and methanol (1:1) as a sheath liquid in the following experiments.

Figure 2 shows a total ion current (TIC) electropherogram of QA- $\beta$-CD with $0.2 \%$ formic acid as a running solution. QA- $\beta$-CD can be separated in the order of decreasing the degree of substitution, and the last peak at 23.8 min having slowest electrophoretic mobility was $\mathrm{QA}(1)-\beta-\mathrm{CD}$, which has one quaternary ammoni-

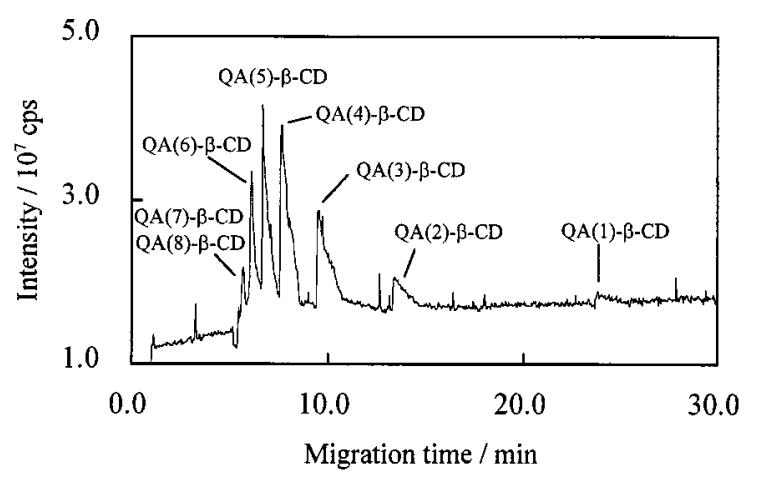

Fig. 2 TIC electropherogram of QA- $\beta$-CD. Sample solution, QA- $\beta$-CD (Lot No. LA 57337) in water $(10 \mathrm{mg} / \mathrm{ml})$; capillary, $50 \mu \mathrm{m}$ i.d. $\times 80 \mathrm{~cm}$ polyacrylamide-coated capillary; separation solution, $0.1 \%$ formic acid; sheath liquid, the mixture of the separation solution and methanol (1:1), $5 \mu \mathrm{l} / \mathrm{min}$; voltage, $(30-5) \mathrm{kV}$; detection, Q1 scan from $\mathrm{m} / \mathrm{z} 300$ to $\mathrm{m} / \mathrm{z}$ 1500, step $0.5 \mathrm{amu}$. Abbreviations are given in the text. um group. As shown in Fig. 3, QA(1)- $\beta$-CD, QA(2)- $\beta$ $\mathrm{CD}, \mathrm{QA}(3)-\beta-\mathrm{CD}, \mathrm{QA}(4)-\beta-\mathrm{CD}$ were detected as each parent ion, but QA- $\beta$-CDs having more than five substituents were not detected as parent ions. These components were detected as either trivalent or tetravalent fragment ions, where the trimethylammonium ion, $\mathrm{HN}^{+}\left(\mathrm{CH}_{3}\right)_{3}$, was cleaved off. Fragmentation was always observed, even when the orifice voltage was extremely decreased. The decrease in the orifice voltage also caused a decrease in the peak intensities of all peaks, including those of molecular ions. Therefore, the ammonium ion should be produced during either the electrospray process or in a charged droplet.

\section{$C E-M S$ of $C M-\gamma-C D$}

When anionic compounds are detected by a negativeion mode of CE-MS, either a neutral buffer solution or an alkaline one is commonly used as both the running solution and the sheath liquid, because it is suitable for the formation of negatively charged droplets during the electrospray process. However, a neural-buffer solution having a sufficient buffer capacity cannot be prepared with ammonium formate or ammonium acetate, and an alkaline buffer solution was not compatible with a polyacrylamide-coated capillary. Therefore, we employed an acetate buffer at $\mathrm{pH} 5.0$ as the running solution. At this $\mathrm{pH}$, the acetate buffer has a low buffer capacity.

Figure 4 shows a TIC electropherogram of $\mathrm{CM}-\gamma-\mathrm{CD}$, where more than six components were identified. When the mass spectrum of each peak was reconstructed, each component was detected as a bivalent ion, as shown in Fig. 5. From Fig. 4, it seems that the average degree of substitution is much higher than 3.2 , which is
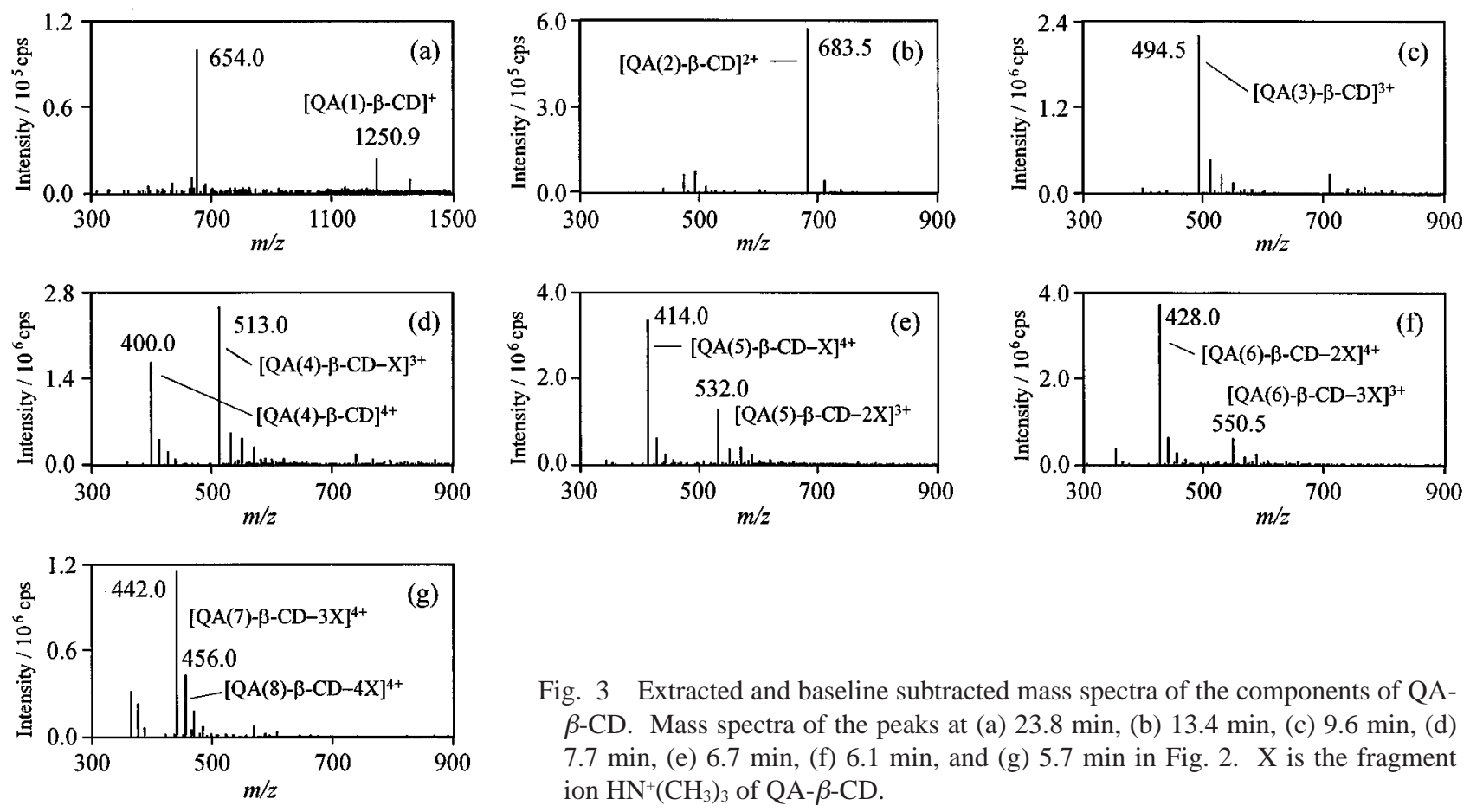

Fig. 3 Extracted and baseline subtracted mass spectra of the components of QA$\beta$-CD. Mass spectra of the peaks at (a) $23.8 \mathrm{~min}$, (b) $13.4 \mathrm{~min}$, (c) $9.6 \mathrm{~min}$, (d) $7.7 \mathrm{~min}$, (e) $6.7 \mathrm{~min}$, (f) $6.1 \mathrm{~min}$, and (g) $5.7 \mathrm{~min}$ in Fig. 2. $\mathrm{X}$ is the fragment ion $\mathrm{HN}^{+}\left(\mathrm{CH}_{3}\right)_{3}$ of QA- $\beta$-CD. 
given as the specification by the supplier. However, the correct value cannot be calculated from this electropherogram, because we have no pure single CD derivative and it is uncertain that the peak intensities of each component are similar.

\section{Comparison of indirect $U V$ detection and MS detection}

On the electropherogram of QA- $\beta$-CD by CZE with the indirect UV detection method, we assumed that the last peak having the slowest electrophoretic mobility was $\mathrm{QA}(1)-\beta$-CD. The preceding peaks were defined as $\mathrm{QA}(2)-\beta-\mathrm{CD}, \mathrm{QA}(3)-\beta-\mathrm{CD}$, and so on. ${ }^{10}$ The composition of $\mathrm{QA}-\beta-\mathrm{CD}$ was calculated from the peak areas, and the result is given in Table 3. Because the average degree of the substitution calculated agreed with the specification, it was concluded that this identification was correct. However, the identification of

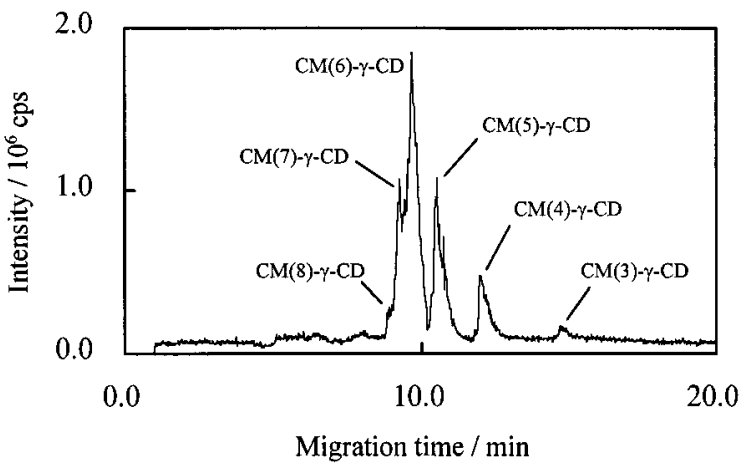

Fig. 4 TIC electropherogram of $\mathrm{CM}-\gamma-\mathrm{CD}$. Conditions: sample solution, CM- $\gamma$-CD (Lot No. CYL-251) in water (5 $\mathrm{mg} / \mathrm{ml})$; capillary, $50 \mu \mathrm{m}$ i.d. $\times 80 \mathrm{~cm}$ polyacrylamide-coated capillary; separation solution, $40 \mathrm{mM}$ ammonium acetate buffer ( $\mathrm{pH} 5.0$ ); sheath liquid, the mixture of the separation solution and methanol (1:1), $5 \mu \mathrm{l} / \mathrm{min}$; voltage, [-30 - -4.5] $\mathrm{kV}$; detection, Q1 scan from $\mathrm{m} / \mathrm{z}, 600$ to $\mathrm{m} / \mathrm{z}, 900$, step 0.5 amu. Abbreviations are given in the text. each peak in the mixture is usually difficult based on only the electropherogram by UV detection. A merit of MS detection is that the peaks can be easily identified based on information concerning the molecular masses. Furthermore, $\mathrm{QA}(7)-\beta-\mathrm{CD}$ and $\mathrm{QA}(8)-\beta-\mathrm{CD}$, which cannot be identified by indirect UV detection, are recognized in QA- $\beta$-CD as minor components. On the other hand, MS detection has several disadvantages for composition analyses. Because we have no pure single CD derivative, the ratio of each component cannot be determined by only the CE-MS. It can be calculated from the peak area of each component by UV detection, because the absorption coefficients of the compounds having similar chemical structure are not different significant. In particular, indirect photometric detection gives a constant sensitivity irrespective of the ionic species, provided that the charge or transfer ratio is identical. However, it is uncertain whether the peak intensity per mole of each component is equal or not in MS detection. Moreover, some components are detected as fragment ions, as shown in Fig. 3. Therefore, simultaneous detection by UV photometry and MS is

Table 3 Composition of QA- $\beta$-CD calculated from the peak areas by CZE analysis with the indirect UV detection

\begin{tabular}{cccc}
\hline CD $^{\mathrm{a}}$ & $\begin{array}{c}\text { Molecular } \\
\text { mass }^{\mathrm{b}}\end{array}$ & Composition $^{\mathrm{c}}, \%$ & $\begin{array}{c}\text { Average degree } \\
\text { of substitution }\end{array}$ \\
\hline QA(1)- $\beta$-CD & 1250 & 10.2 & \\
QA(2)- $\beta$-CD & 1366 & 15.8 & \\
QA(3)- $\beta$-CD & 1482 & 21.5 & 3.7 \\
QA(4)- $\beta$-CD & 1598 & 20.4 & \\
QA(5)- $\beta$-CD & 1714 & 14.1 & \\
QA(6)- $\beta$-CD & 1830 & 18.0 & \\
\hline
\end{tabular}

a. Abbreviations are given in the text.

b. The values do not include chloride ions in the quaternary ammonium substituents.

c. Average of three determinations.
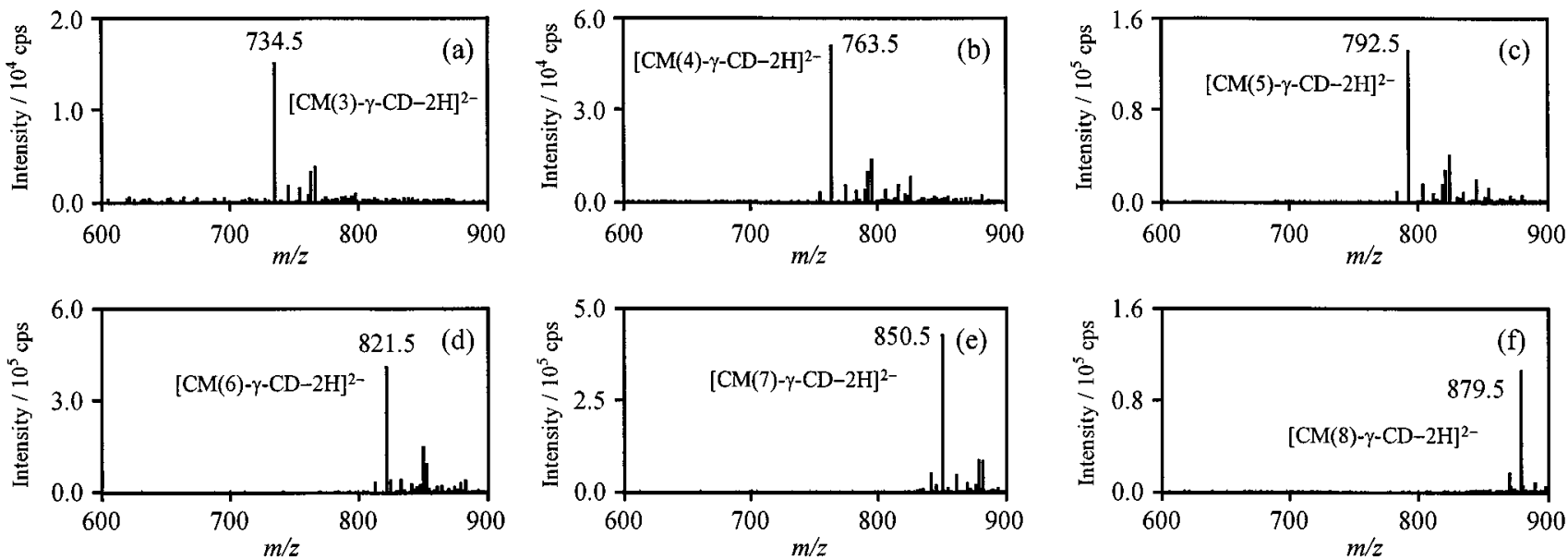

Fig. 5 Extracted and baseline subtracted mass spectra of the components of CM- $\gamma$-CD. Mass spectra of the peaks at (a) 14.7 min, (b) $12.0 \mathrm{~min}$, (c) $10.5 \mathrm{~min}$, (d) $9.7 \mathrm{~min}$, (e) $9.3 \mathrm{~min}$, and (f) 8.9 min in Fig. 4. 
preferred for composition analysis. The current commercial CE instruments can be easily coupled to the MS instrument without any special modification in addition to simultaneous UV detection. However, there are some problems caused by simultaneous detection. The first is a mismatch of the outside diameter of the capillary: the commercial ISP interface for API-300 needs a capillary less than $200 \mu$ m o.d.; most commercial CE instruments use $375 \mu \mathrm{m}$ o.d. capillaries. In order to make a narrow o.d. capillary compatible with the $375 \mu \mathrm{m}$ slit of the UV detector, a co-axial detection cell was prepared at the detection window of the capillary. A $150 \mu \mathrm{m}$ o.d. capillary was protruded through a wide-bore capillary ( $200 \mu \mathrm{m}$ i.d and $375 \mu \mathrm{m}$ o.d.) of 5 $\mathrm{cm}$ in length having a clear window for the detection window. The positions of both UV detection windows were matched, and both ends of the wide-bore capillary were glued after the CE capillary was incorporated into a user-assembled capillary cartridge. Although the coaxial cell made simultaneous detection, the baseline of the UV detection was more unstable than that of conventional CE analyses with a $375 \mu \mathrm{m}$ o.d. capillary. The second is the long capillary. For simultaneous detection, more than a $100 \mathrm{~cm}$ capillary is needed. A capillary having a longer total length causes a longer analysis time. Third is the short distance to the UV detection window: $22 \mathrm{~cm}$ of $110 \mathrm{~cm}$ in this study. The effective length for UV detection is only a minor fraction of the total length. Since the UV absorbing reagent for indirect detection cannot be used for CEMS, the composition of UV non-absorbing analyses must be performed by either UV or MS detection separately. In order to perform a simultaneous determination by UV photometry and MS, further improvements of both instruments and the operation conditions are necessary. However, CE-MS will be a powerful tool for a composition analysis of mixtures in the future.
The authors gratefully acknowledge Dr. M. Miyagi (Takara Shuzo Co.) and Ms. K. Minoura (Yokogawa Analytical Systems) for their supports on the coupling of the CE instrument to API-300, and Mr. T. Kaneko (Sigma Aldrich Japan Inc.) for his supports on the separation of QA- $\beta-C D$.

\section{References}

1. H. Nishi and S. Terabe, J. Chromatogr. A, 694, 245 (1995).

2. S. Fanali, J. Chromatogr. A, 735, 77 (1996).

3. B. Chankvetadze, G. Endresz and G. Blaschke, Chem. Soc. Rev., 1996, 141.

4. A. M. Stalcup and K. H. Gahm, Anal. Chem., 68, 1360 (1996).

5. Y. Tanaka, M. Yanagawa and S. Terabe, J. High Resolut. Chromatogr., 19, 421 (1996).

6. E. C. Rickard, R. J. Bopp, D. J. Skanchy, K. L. Chetwyn, B. Pahlen and J. F. Stobaugh, Chirality, 8, 108 (1996).

7. J. Szemán, K. Ganzler, A. Salgó and J. Szejtli, J. Chromatogr. A, 728, 423 (1996).

8. R. J. Tait, D. J. Skanchy, D. P. Thompson, N. C. Chetwyn, D. A. Dunshee, R. A. Rajewski, V. J. Stella and J. F. Stobaugh, J. Pharm. Biomed. Anal., 10, 615 (1992).

9. B. Chankvetadze, G. Endresz, G. Blaschke, M. Juza, H. Jakubetz and V. Schurig, Carbohydr. Res., 287, 139 (1996).

10. Y. Tanaka and S. Terabe, J. Chromatogr. A, 781, 151 (1997).

11. J. A. Olivares, N. T. Nguyen, C. R. Yonker and R. D. Smith, Anal. Chem., 59, 1230 (1987).

12. J. Cai and J. Henion, J. Chromatogr. A, 703, 667 (1995).

13. M. Nakatani, A. Shibukawa and T. Nakagawa, Biol. Pharm. Bull., 16, 1185 (1993).

14. F. Foret, T. J. Thompson, P. Vouros, B. L. Karger, P. Gebauer and P. Bocek, Anal. Chem., 66, 4450 (1994).

(Received October 13, 1997)

(Accepted November 7, 1997) 